of the lack of communication between scientific disciplines. His remedy-the creation of a special sort of literature-is all very well, but could lead to scientific authoritarianism.

D. M. Mackay, in his paper on self-fulfilling and selfstultifying prophecies in the social sciences, completely misses the point of his own argument. He postulates a universe populated by Laplacean demons and quickly gets entangled in paradoxes. Instead of taking this as a refutation of the sort of determinism that he is considering, he uses it as an excuse to launch a thoroughly subjectivist and positivist theory of knowledge, of which the following quotation is fairly representative: "In this domain [social science] the idea that two individuals must have the same belief (expressible by the same proposition) in order that each should believe rightly, is transparently false".

This book illustrates fairly well some of the less good aspects of modern philosophy of science-particularly subjectivism-and other papers are only now groping towards solutions proposed by Popper in 1934. On this count it can scarcely be recommended, especially in view of its high price. Unfortunately, it is still further marred by barbarisms and misprints, some of them seriously confusing.

David Miller

\section{PERSPECTIVES IN PHYSICAL METALLURGY}

Physical Metallurgy

Edited by R. W. Cahn. Pp. xxii + 1,100. (Amsterdam: North-Holland Publishing Company, 1965.) $220 \mathrm{~s}$.

PHYSICAL Metallurgy is a massive volume intended to present an exhaustive account of the subject in the mid-1960's, yet keeping within the bounds of two covers. The material has been edited by $R$. W. Cahn and is divided into twenty chapters written by twenty-one authors. There is an international spread of contributors, which is to be welcomed, but the United States maintains its aura of industrious authorship and somewhat dominates this book by contributing no less than twelve of the chapters (United Kingdom, seven; France, one; Germany, one; Japan, one).

The advantages of collecting the efforts of many authors together lie in ensuring undisputed expertise in each field and, for an ambitious scheme like this, in hoping to reduce the time between the concept of the project and its execution. The disadvantages accrue from a potential unevenness of treatment and too loose a relation between the contributions. In this case it seems that the editor had a clear vision of what he wanted, that he conceived the book as a whole and then went out to persuade his collaborators to write closely within the set framework.

In detail this framework has some interesting and original variants, but in its broad sweep it follows the pattern which has been established during the past decade or so as the accepted structure of physical metallurgy. Thus the subject-matter proceeds from considerations of metallic bonding and electron theory through solid solutions, intermediate phases, a sidelong glance at thermodynamics, phase diagrams, diffusion, solidification, transformations, metallography and microstructure to dislocations and point defects, and then to some five chapters on mechanical behaviour. The editor himself contributes a chapter on recovery and recrystallization, and the book ends with chapters on magnetic properties, and the properties of super-pure metals.

The introductory chapter on historical development by R. F. Mehl deserves special mention. Not only was this an unusual and valuable editorial idea but the chapter is also a compelling account, giving balance and perspective to the subject.
In a short review, when the canvas is spread so broadly and the treatment is so exhaustive, it would be impossible to indulge in the minutiae of criticism-each chapter could be a separate monograph and some, such as Christian's on phase transformations, amounting to nearly 40,000 words, are text-books in themselves. It is much more profitable to stand back and to ask what perspectives of the subject the book projects. First, does it achieve its objectives ? The editor defines these, in his preface, as aiming to provide a general text directed at senior undergraduates, but to be used also by postgraduates and as a base for experienced research workers entering fields of physical metallurgy new to them. I consider that the book will be successfully used for each of these purposes, and for most libraries its purchase will be essential and inevitable. It is not intended to be, and could not be, an introductory text, although some repetition of what is found in more elementary books cannot be avoided and is, indeed, desirable.

In spite of its vastness, the book has some blind spots. Corrosion and a coherently considered treatment of surface phenomena are absent. Although there is a whole chapter on magnetism and another on super-pure metals, semiconductors and super-conductors do not get much of a look-in-naturally the 'electron theory' and the 'intermediate phase' boys have a go, but there the treatment ends. Irradiation effects and 'gases in metals' find little favour with the authors. And then steel: surely it is inadequate (or prophetic ?) to find its mention almost entirely confined to the historical chapter that introduces the book? Did a contributor let the editor down? This omission prompts a final reflexion. Almost nowhere does the text refer to real alloys-the sort that engineers and metallurgists grapple with daily to earn a living. So successful have physical metallurgists been in creating a 'natural philosophy' around their subject, they have been able to distil off, from the crude amalgam of industrial practice, essential scientific concepts that do not recognize the limited classification into ferrous, non-ferrous, brasses, bronzes and the rest of the glory of the classical repertory.

This is truly philosophical advance and the book admirably demonstrates how far we have gone-but let us not forget that metallurgists are also important in earning a living for the world. J. G. BALL

\section{AERODYNAMICS OF HYPERSONIC FLIGHT}

Elements of Hypersonic Aerodynamics

By Dr. R. N. Cox and Dr. L. F. Crabtree. (Applied Physics Guides.) Pp. xii + 243. (London: The English Universities Press, Ltd., 1965.) 35s. net.

$\mathrm{T}$ HE characteristics of air flow at hypersonic (or high supersonic) speeds have a deceptive simplicity. The behaviour of a perfect gas at large Mach numbers is generally calculable and it has distinctive features well in evidence for Mach numbers as low as 5, notably that small changes in Mach number are associated with large changes of temperature rather than of flow pattern. However, the approximation of a perfect gas becomes increasingly less valid with increase of speed because of the associated high temperatures; molecular vibration, dissociation and even ionization effects become important. Boundary layers on bodies thicken and threaten to fill the narrow regions of air flow aft of the leading edge shocks, and interaction effects curve these shocks and introduce large entropy gradients. The subject is therefore a complex one, particularly when flight at very high altitudes and low densities is included for which the air can no longer be regarded as a continuum.

This little book ambitiously tries to survey the whole subject. The first and larger part is concerned with the flow of an inviscid perfect gas. It covers the basic flow 